\title{
Synthesis and Mesogenic Property of New Bent-Core Molecules with Semifluorinated Alkanes
}

\author{
E-Joon Choi, ${ }^{*}$ Hoo-Sik Sim, Liang-Chy Chien, ${ }^{\dagger}$ and Soo-Min Lee \\ Department of Polymer Science and Engineering, Kumoh National Institute of Technology, Gumi, \\ Gyungbuk730-701, Korea. E-mail: ejchoi@kumoh.ac.kr \\ ${ }^{\dagger}$ Liquid Crystal Institute, Kent State University, Kent, Ohio 44242, USA \\ ¿Department of Chemistry, Hannam University, Daejeon 306-791, Korea \\ Received July 22, 2010, Accepted December 22, 2010
}

Key Words: Bent-core LC, Smectic phases, Shape biaxiality, Shape amphiphilicity

One of extremely fascinating areas in the recent research fields of liquid crystals is the generation of the non-conventional smectic mesophase. From the structural point of view, molecular biaxiality have been recognized, targeted, and adopted for this purpose. ${ }^{1}$ Shape amphiphilicity is one of the possible ways to induce novel mesogenic biaxiality. Amphiphilic molecules consist of two incompatible parts by their chemical nature such as hydrophilic/hydrophobic, stiff/flexible, aliphatic/conjugated aromatic, and polar (polarizable)/non-polar (non-polarizable). For instance, semifluorinated alkanes (SFA) contain two different segments within their molecules, namely a hydrocarbon and a perfluorocarbon fragment. Mahler et $a l^{2}$ reported that one representative example of SFA, (perfluorodecyl)decane $\left(\mathrm{F}\left(\mathrm{CF}_{2}\right)_{10}\left(\mathrm{CH}_{2}\right)_{10} \mathrm{H}\right.$ or simply $\left.\mathrm{F} 10 \mathrm{H} 10\right)$, forms a smectic $\mathrm{B}$ mesophase. Moreover, Tournilhac et al. ${ }^{3}$ first reported that a ferroelectric repolarizable mesophase is obtained with nonchiral polyphilic molecules consisting of a conventional paraconjugated mesogenic unit and a SFA moiety.

In 1996, Takezoe and Watanabe's Group ${ }^{4}$ reported the first obvious example of an antiferroelectric smectic $\mathrm{C}$ phase derived from an achiral banana-shaped molecule, ascribing the polar packing of the bent-core mesogen with $C_{2 \mathrm{~V}}$ symmetry. One year later, the Boulder Group ${ }^{5}$ proposed a chiral layer structure of the polar smectic $\mathrm{C}(\mathrm{SmCP})$ phase of a bananashaped achiral molecule, which possesses a handedness depending on the tilted molecular direction. Since then, in order to understand structure-property relationships many banana-shaped molecules with Schiff-base linkages have been synthesized by a number of research groups. ${ }^{6}$ In general their structures consist of a rigid aromatic conjugated bent-core unit and two flexible aliphatic terminal groups. It should be noteworthy that the flexible terminal group (e.g. polymethylene) can assist the rigid bent-core unit in producing the mesophase. Thus, one can expect that by the introduction of perfluoroalkyl chains into terminal positions of mesogens, the mesophase stability is generally increased because of the stiffness of such chains. However, to the best of our knowledge, there has been no report on synthesis and mesogenic properties of bent-core molecules with SFA terminal chains: in 2000, Kovalenko et al. ${ }^{7}$ found that the perfluoroalkyl chains (F9H2 and F11H2) in bent-core molecules can be decoupled from the aromatic part of the molecules by aliphatic spacers. However, this case cannot be counted as a real example of the bent-core molecules with the SFA synthon, because their molecules contain only a long fluorocarbon fragment $\left(\mathrm{C}_{4} \mathrm{~F}_{9}\right.$ - or $\mathrm{C}_{5} \mathrm{~F}_{11}$ - group) without an enough long hydrocarbon fragment (- $\mathrm{CH}_{2}$ - moiety).

In this study, we have synthesized new polyphilic bent-core molecules with a real SFA terminal chain (F8H6 or F8H10) and investigated their mesogenic properties. Synthetic route to

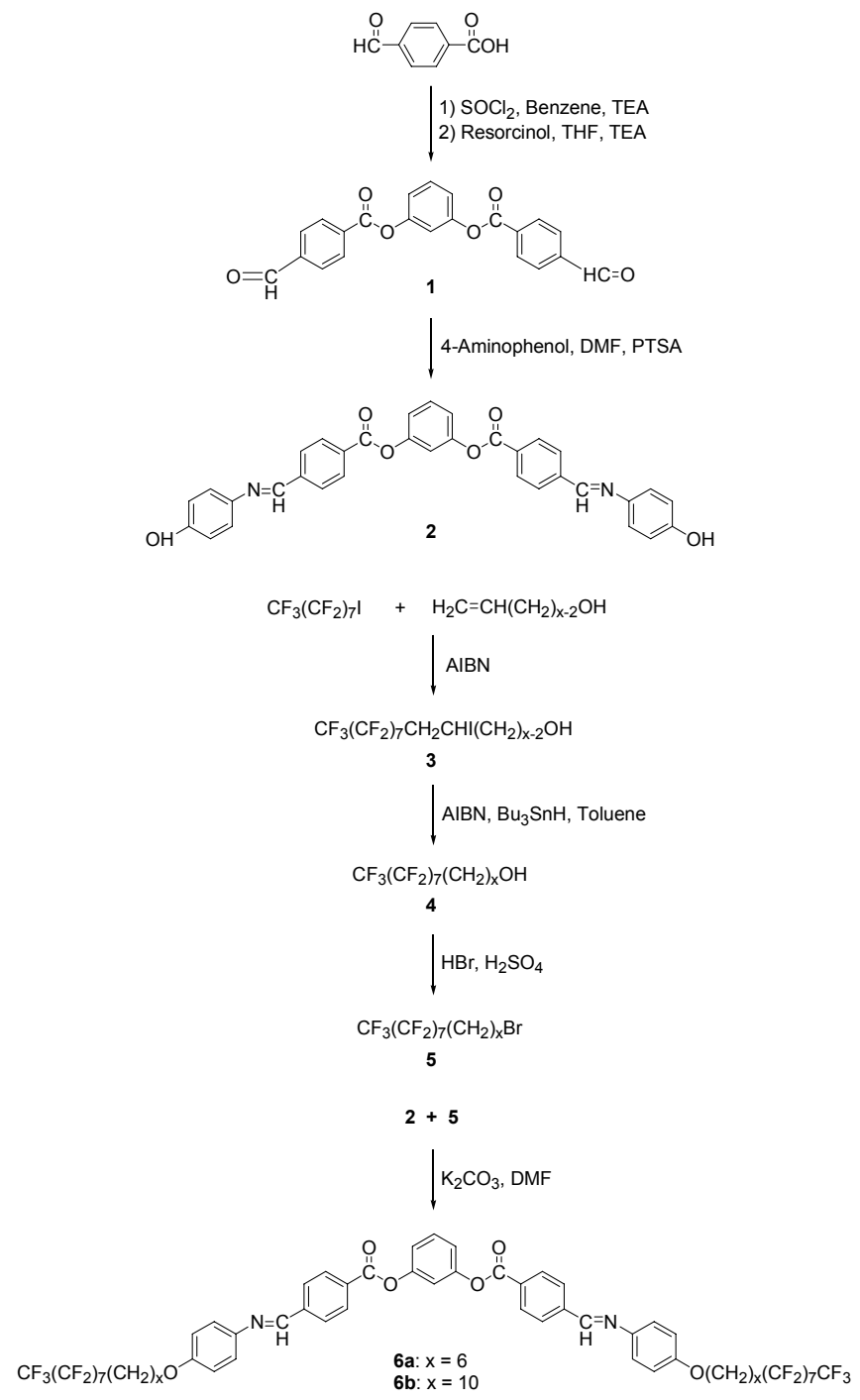

Figure 1. Synthetic route to bent-core compounds. 
Table 1. Transition behavior of bent-core compounds

\begin{tabular}{cccccc}
\hline Compound & SFA & $\mathrm{T}_{\mathrm{m}}\left({ }^{\circ} \mathrm{C}\right)$ & $\begin{array}{c}\Delta \mathrm{H}_{\mathrm{m}} \\
(\mathrm{kJ} / \mathrm{mol})\end{array}$ & $\mathrm{T}_{\mathrm{i}}\left({ }^{\circ} \mathrm{C}\right)$ & $\Delta \mathrm{T}^{a}\left({ }^{\circ} \mathrm{C}\right)$ \\
\hline $\mathbf{6 a}$ & $\mathrm{F} 8 \mathrm{H} 6$ & 137 & 11.9 & 145 & 8 \\
$\mathbf{6 b}$ & F8H10 & 124 & 9.0 & 134 & 10 \\
\hline
\end{tabular}

${ }^{a} \Delta \mathrm{T}=\mathrm{T}_{\mathrm{i}}-\mathrm{T}_{\mathrm{m}}$.

compounds is shown in Fig. 1. The bent-core compounds with a SFA terminal group (compound $\mathbf{6 a}$ and $\mathbf{b}$ ) were obtained in six steps. Synthesis of the synthon with the bent-core mesogen (compound 2) was started by reaction of 4-formylbenzoic acid with resorcinol. And then, obtained compound $\mathbf{1}$ with a formyl end group reacted with aminophenol to give compound $\mathbf{2}$ with a hydroxyl end group. Synthesis of the SFA synthon (compound 5) was started by 1,2-addition of perfluoroalky iodide to an $\alpha$-hydroxy- $\omega$-alkene followed by reduction. Resulting compound $\mathbf{4}$ behaves like a normal primary alcohol and can be reacted with $\mathrm{HBr}$ to give compound $\mathbf{5}$ with a bromo-substituent. Finally compound $\mathbf{6 a}$ and $\mathbf{b}$ could be prepared by etherification of compound $\mathbf{2}$ with compound $\mathbf{5}$ in a basic medium. The structures of all these compounds were characterized by FT/IR and NMR spectroscopy. The resultant spectral data were in accordance with expected formulae.

The thermal transition temperatures were determined by differential scanning calorimeter (DSC) and reconfirmed by polarizing optical microscope (POM). In Table 1, the DSC results are presented. The values of melting $\left(\mathrm{T}_{\mathrm{m}}\right)$ and isotropization temperatures $\left(\mathrm{T}_{\mathrm{i}}\right)$ of compound $\mathbf{6 a}$ with $\mathrm{F} 8 \mathrm{H} 6$ were about $10{ }^{\circ} \mathrm{C}$ higher than those of compound $\mathbf{6 b}$ with F8H10. While the enthalpy change for melting $\left(\Delta \mathrm{H}_{\mathrm{m}}\right)$ of the former compound was about $3 \mathrm{~kJ} / \mathrm{mol}$ higher than that of the latter compound, the temperature range of mesophase formation for the former was $2{ }^{\circ} \mathrm{C}$ narrower than that for the latter. Note that as the number of carbon in the hydrocarbon fragment decreases, the entropy change for melting decreases whereas the enthalpy change for chain packing increases. Optical textures were observed using a POM attached with a heating stage. Because optical textures (see Fig. 2) were very similar to ones observed in the SFA derivatives, ${ }^{2,3}$ we suggested that the two compounds could form a non-conventional smectic mesophase. In conclusion, from the DSC and POM results we could confirm that the SFA end groups can play an important role for the bent-core mesogens to form the smectic mesophase (see Fig. 3). However, in order to understand completely the unique bent-shaped conformation

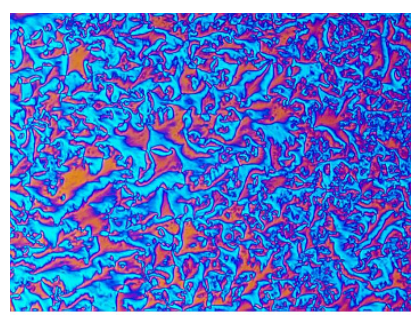

(a)

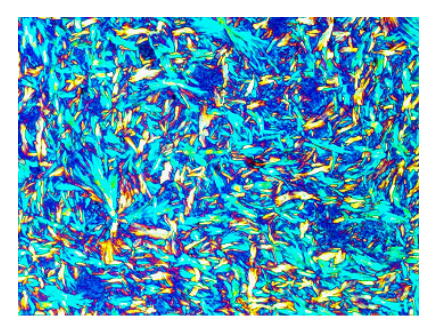

(b)
Figure 2. Cross-polarizing optical microphotographs (magnification X250): (a) 6a, $T=144^{\circ} \mathrm{C}$, on heating; (b) $6 \mathbf{b}, T=106^{\circ} \mathrm{C}$, on cooling a super cooling was observed and the texture represents a mesophase.

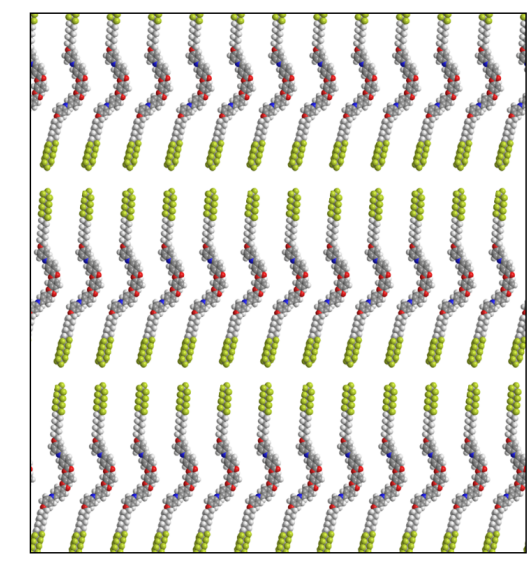

Figure 3. Possible smectic layer structure of F8H8 compound.

and smectic layer structure formed by the polyphilic bent-core molecules, more studies are needed.

\section{Experimental Section}

Synthesis. The compounds were prepared by modification of the synthetic procedures reported in the literature. ${ }^{8,9}$

1,3-Phenylene bis[4-(4-hydroxyphenyliminomethyl)benzoates] (2): 4-Aminophenol (1.02 g, $9.34 \mathrm{mmol})$ and 2 drops of $p$-toluenesulfonic acid were added in $50 \mathrm{~mL}$ of DMF. To this mixture was added a solution of 1,3-phenylene bis(4-formylbezoate) $(1.00 \mathrm{~g}, 2.67 \mathrm{mmol})$ in $50 \mathrm{~mL}$ of DMF. The mixture was heated to $155{ }^{\circ} \mathrm{C}$ with stirring for $4 \mathrm{hrs}$. After cooling, the reaction mixture was poured into water, and formed precipitate washed with water and ethanol thoroughly. The crude product was purified by recrystallization from a mixture of 1,4-dioxane/ ethyl acetate $(1: 1 \mathrm{v} / \mathrm{v})$. Yield: $95 \%$. IR ( $\mathrm{KBr}$ pellet, $\left.\mathrm{cm}^{-1}\right): 3100$ $($ aromatic $=\mathrm{CH}, \mathrm{st}), 2934,2865($ aliphatic $\mathrm{CH}, \mathrm{st}), 1740(\mathrm{C}=\mathrm{O}$, st), $1610(\mathrm{C}=\mathrm{N}, \mathrm{st}), 1580,1500$ (aromatic $\mathrm{C}=\mathrm{C}, \mathrm{st}), 1250,1200$, $1130,1060(\mathrm{CO}, \mathrm{st}) .{ }^{1} \mathrm{H}$ NMR spectrum (DMSO- $d_{6}, \delta$ in ppm) $9.63(2 \mathrm{H}, \mathrm{s}, \mathrm{ArOH}), 8.77(2 \mathrm{H}, \mathrm{s}, \mathrm{ArCH}=\mathrm{N}), 8.26-8.22(4 \mathrm{H}, \mathrm{d}$,

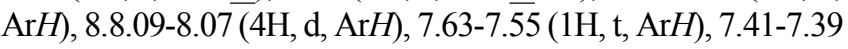
$(1 \mathrm{H}, \mathrm{t}, \mathrm{ArH}), 7.33-7.27$ (6H, m, ArH), 6.84-6.80 (4H, m, ArH).

5-Iodo,7,7,8,8,9,9,10,10,11,11,12,12,13,13,14,14,14-heptadecafluorobutadecan-1-ol (3a): Perfluorooctyl iodide (5.0 g, $9.0 \mathrm{mmol})$ was dropwisely added to 5-hexen-1-ol (1.35 g, 13.0 $\mathrm{mmol})$ at $40{ }^{\circ} \mathrm{C}$. AIBN $(0.070 \mathrm{~g}, 0.45 \mathrm{mmol})$ was added to the stirred solution at $5 \mathrm{~min}$ intervals over the next $45 \mathrm{~min}$. After final AIBN addition, the solution was stirred at $80{ }^{\circ} \mathrm{C}$ for $5 \mathrm{~h}$ and then was cooled to room temperature to give a crude product as a pink wax, which was used without a further purification.

9-Iodo,12,12,13,13,14,14,15,15,16,16,17,17,18,18,19,19, 19-heptadecafluorooctadecan-1-ol (3b): Perfluorooctyl iodide $(5.0 \mathrm{~g}, 9.0 \mathrm{mmol})$ was dropwisely added to 9-decen-1-ol (2.1 g, $13.0 \mathrm{mmol})$ at $40{ }^{\circ} \mathrm{C}$. AIBN $(0.070 \mathrm{~g}, 0.45 \mathrm{mmol})$ was added to the stirred solution at $5 \mathrm{~min}$ intervals over the next $45 \mathrm{~min}$. After final AIBN addition, the solution was stirred at $80{ }^{\circ} \mathrm{C}$ for $5 \mathrm{~h}$ and then was cooled to room temperature to give a crude product as a pink wax, which was used without a further purification.

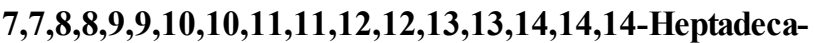
fluorobutadecan-1-ol (4a): The $9.0 \mathrm{mmol}$ of precursor iodo- 
compound (3a) was added to toluene $(10 \mathrm{~mL})$ solution of AIBN $(0.15 \mathrm{~g}, 0.90 \mathrm{mmol})$ and tributyltin hydride $(5.24 \mathrm{~g}, 18 \mathrm{~mol})$, and was stirred at $80^{\circ} \mathrm{C}$ over $20 \mathrm{~h}$. The resulting solution was poured into a mixture of methanol and water $(3: 1 \mathrm{v} / \mathrm{v})$ to give a precipitate. After filtration, the precipitate was dried under vacuum at $25{ }^{\circ} \mathrm{C}$. After filtration, the crude product was dried under vacuum at $25^{\circ} \mathrm{C}$, and was recrystallized from toluene to form a white powdered solid. IR (KBr pellet, $\left.\mathrm{cm}^{-1}\right) 3320(\mathrm{OH}$, st), 2900 (aliphatic C-H, st), 1250 (aliphatic $\mathrm{CF}_{3}$, st), 1100 (alipahtic $\mathrm{CF}_{2}$, st).

$12,12,13,13,14,14,15,15,16,16,17,17,18,18,19,19,19-Н е р-$ tadecafluorooctadecan-1-ol (4b): The $9.0 \mathrm{mmol}$ of precursor iodo-compound $(\mathbf{3 b})$ was added to toluene $(10 \mathrm{~mL})$ solution of AIBN (0.15 g, $0.90 \mathrm{mmol})$ and tributyltin hydride (5.24 g, 18 $\mathrm{mol}$ ), and was stirred at $80^{\circ} \mathrm{C}$ over $20 \mathrm{~h}$. The resulting solution was poured into a mixture of methanol and water $(3: 1 \mathrm{v} / \mathrm{v})$ to give a precipitate. After filtration, the crude product was dried under vacuum at $25^{\circ} \mathrm{C}$, and was recrystallized from toluene to form a white powdered solid. IR (KBr pellet, $\left.\mathrm{cm}^{-1}\right) 3420(\mathrm{OH}$, st), 2900 (aliphatic CH, st), 1250 (aliphatic $\mathrm{CF}_{3}$, st), 1100 (alipahtic $\mathrm{CF}_{2}$, st).

1-Bromo-7,7,8,8,9,9,10,10,11,11,12,12,13,13,14,14,14heptadecafluorobutadecane (5a): A mixture of concentrated sulphuric acid and hydrobromic acid $(1: 3 \mathrm{w} / \mathrm{w})$ was slowly added to the precursor polyfluorinated alcohol (4a) $(0.80 \mathrm{~g}, 1.5 \mathrm{mmol})$. The mixture was heated at $130-140{ }^{\circ} \mathrm{C}$ for $3 \mathrm{~h}$ without stirring. After cooling, the mixture was poured into cold water. The aqueous phase was extracted with dichloromethane and washed with sulphuric acid, twice with water, once with a sodium thiosulphate solution and again with water. After evaporation, the crude product was obtained as a yellow wax. IR ( $\mathrm{KBr}$ pellet, $\mathrm{cm}^{-1}$ ) 2920 (aliphatic C-H, st), 1250 (aliphatic $\mathrm{CF}_{3}, \mathrm{st}$ ), 1100 (alipahtic $\mathrm{CF}_{2}$, st), $760(\mathrm{CBr}, \mathrm{st})$.

1-Bromo-12,12,13,13,14,14,15,15,16,16,17,17,18,18,19,19, 19-heptadecafluorooctadecane (5b): A mixture of concentrated sulphuric acid and hydrobromic acid $(1: 3 \mathrm{w} / \mathrm{w})$ was slowly added to the precursor polyfluorinated alcohol (4b) $(0.42 \mathrm{~g}$, $0.75 \mathrm{mmol})$. The mixture was heated at $130-140{ }^{\circ} \mathrm{C}$ for $4 \mathrm{~h}$ without stirring. After cooling, the mixture was poured into cold water. The aqueous phase was extracted with dichloromethane and washed with sulphuric acid, twice with water, once with a sodium thiosulphate solution and again with water. After evaporation, the crude product was obtained as a yellow wax. IR (KBr pellet, $\mathrm{cm}^{-1}$ ) 2900 (aliphatic $\mathrm{CH}, \mathrm{st}$ ), 1250 (aliphatic $\mathrm{CF}_{3}$, st), 1100 (alipahtic $\mathrm{CF}_{2}$, st), $750(\mathrm{CBr}, \mathrm{st}$ ).

1,3-Phenylene bis[4-(4-heptadecafluorobutadecaoxyphenyliminomethyl)benzoate] (6a): Potassium carbonate ( $0.17 \mathrm{~g}, 1.2$ mmol) was added to a DMF $(20 \mathrm{~mL})$ solution of 1,3-phenylene bis[4-(4-hydroxyphenyliminomethyl)benzoate (2) (0.17 g, $0.62 \mathrm{mmol}$ ). The mixture was refluxed at $80{ }^{\circ} \mathrm{C}$ until its color was changed from dark pink to pale brown. And then to the mixture was added the precursor bromo-compound (5a) $(0.36 \mathrm{~g}$, $0.62 \mathrm{mmol}$ ), and was stirred at $120{ }^{\circ} \mathrm{C}$ for another $8 \mathrm{~h}$. The resulting pale pink solution was poured into water to give a precipitate, which was recovered by a centrifuge. After washing with distilled water, methanol and DMF thoroughly, the product was obtained as a pale brown solid. IR (KBr pellet, $\mathrm{cm}^{-1}$ ) $3100($ aromatic $=\mathrm{CH}, \mathrm{st}), 2920($ aliphatic $\mathrm{CH}, \mathrm{st}), 1740(\mathrm{C}=\mathrm{O}$, st), $1610(\mathrm{C}=\mathrm{N}, \mathrm{st}), 1580,1500$ (aromatic $\mathrm{C}=\mathrm{C}, \mathrm{st}$ ), 1250 (aliphatic $\mathrm{CF}_{3}$, st), 1200, 1130, 1060 (CO, st), 1100 (alipahtic $\mathrm{CF}_{2}$, st). ${ }^{1} \mathrm{H}-\mathrm{NMR}$ spectrum (DMSO- $d_{6}, \delta$ in ppm) $9.39(2 \mathrm{H}, \mathrm{s}$, $\operatorname{ArC} \underline{H}=\mathrm{N}), 8.82-8.27(9 \mathrm{H}, \mathrm{d}, \mathrm{Ar} H), 8.05-7.72(5 \mathrm{H}, \mathrm{d}, \mathrm{Ar} H)$, 7.62-7.21 (5H, t, $\mathrm{ArH}), 4.51-4.11\left(3 \mathrm{H}, \mathrm{s}, \mathrm{CF}_{2} \mathrm{CH}\right)$.

1,3-Phenylene bis[4-(4-heptadecafluorooctadecaoxyphenyliminomethyl)benzoate] (6b): Potassium carbonate $(0.11 \mathrm{~g}$, $3.2 \mathrm{mmol})$ was added to a DMF $(20 \mathrm{~mL})$ solution of 1,3phenylene bis[4-(4-hydroxyphenyliminomethyl)benzoate (2) $(0.12 \mathrm{~g}, 0.20 \mathrm{mmol})$. The mixture was refluxed at $80{ }^{\circ} \mathrm{C}$ until its color was changed from dark pink to pale brown. And then to the mixture was added the precursor bromo-compound (5b) $(0.27 \mathrm{~g}, 0.40 \mathrm{mmol})$, and was stirred at $120^{\circ} \mathrm{C}$ for another $8 \mathrm{~h}$. The resulting pale pink solution was poured into water to give a precipitate, which was recovered by a centrifuge. After washing with distilled water, methanol and DMF thoroughly, the product was obtained as a pale brown solid. IR ( $\mathrm{KBr}$ pellet, $\left.\mathrm{cm}^{-1}\right) 3100($ aromatic $=\mathrm{CH}, \mathrm{st}), 2900($ aliphatic C-H, st $) .1740$ $(\mathrm{C}=\mathrm{O}, \mathrm{st}), 1610(\mathrm{C}=\mathrm{N}, \mathrm{st}), 1580,1500$ (aromatic $\mathrm{C}=\mathrm{C}, \mathrm{st}), 1250$ (aliphatic $\mathrm{CF}_{3}$, st), 1200, 1130, 1060 (CO, st), 1100 (alipahtic $\left.\mathrm{CF}_{2}, \mathrm{st}\right) .{ }^{1} \mathrm{H}-\mathrm{NMR}$ spectrum $\left(\mathrm{CF}_{3} \mathrm{CO}_{2} \mathrm{D}, \delta\right.$ in ppm $) 9.37(2 \mathrm{H}, \mathrm{s}$, $\operatorname{ArCH}=\mathrm{N}), 8.81-8.25(9 \mathrm{H}, \mathrm{d}, \mathrm{ArH}), 8 . .05-7.62(5 \mathrm{H}, \mathrm{d}, \mathrm{ArH})$, 7.52-7.22 (5H, t, $\mathrm{ArH}), 4.52-4.10\left(3 \mathrm{H}, \mathrm{s}, \mathrm{CF}_{2} \mathrm{CH}\right)$.

\section{Instrumentation}

IR and NMR spectra were obtained by a Jasco 300E FT/IR and Brucker DPX $200 \mathrm{MHz}$ NMR spectrometers, respectively. The phase transition temperatures were determined by differential scanning calorimeter (duPont TA 910 DSC) and polarizing optical microscope (Zeiss, Jenapol). DSC measurements were performed in a $\mathrm{N}_{2}$ atmosphere. The DSC heating and cooling rates were of $20{ }^{\circ} \mathrm{C} / \mathrm{min}$. Optical textures were observed by a polarizing microscope equipped with a camera and a thermocontroller (Mettler FP82HT).

Acknowledgments. This work was supported by the National Research Foundation of Korea (NRF) grant funded by Korea government (MEST) (No. R01-2008-000-11521-0).

\section{References}

1. Bruce, D. W. The Chemical Record 2004, 4, 10.

2. Mahler, W.; Guillon, D.; Skoulios, A. Mol. Cryst. Liq. Crys. Letters 1985, 2(3-4), 111.

3. Tournilhac, F. G.; Bosio, L.; Simon, J.; Blinov, L. M.; Yablonsky, S. V. Liq. Cryst. 1993, $2,405$.

4. Niori, T.; Sekine, T.; Watanabe, J.; Furukawa, T.; Takezoe, H. J. Mater. Chem. 1996, 6, 1231.

5. Link, D. R.; Natale, G.; Shao, R.; Maclennan, J. E.; Clark, N. A.; Korblova, E.; Walba, D. M. Science 1997, 278, 1924.

6. (a) Takezoe, H.; Takanishi, Y. Jpn. J. Appl. Phys. 2006, 45, 597. (b) Amarantha Reddy, R.; Tschierske, C. J. Mater. Chem. 2006, 16, 907.

7. Kovalenko, L.; Weissflog, W.; Grande, S.; Diele, S.; Pelzl, G.; Wirth, I. Liq. Cryst. 2000, 27(5), 683.

8. (a) Lee, C. K.; Chien, L. C. Liq. Cryst. 1999, 26, 609. (b) Choi, E-J.; Cui, X.; Ohk, C.-W.; Zin, W.-C.; Lee, J.-H.; Lim, T.-K.; Jang, W.-G. J. Mater. Chem. 2010, 20, 3743.

9. Rabolt, J. F.; Russell, T. P.; Twieg, R. J. Macromolecules 1984, 17,2786 . 